\begin{tabular}{|c|c|c|}
\hline 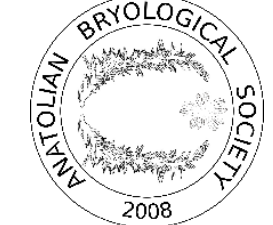 & $\begin{array}{l}\text { http://dergipark.gov.tr/anatolianbryology } \\
\text { DOI: } 10.26672 / \text { anatolianbryology.347796 }\end{array}$ & $\begin{array}{c}\text { Anatolian Bryology } \\
\text { Anadolu Briyoloji Dergisi } \\
\text { Research Article } \\
\text { ISSN:2149-5920 Print } \\
\text { e-ISSN:2458-8474 Online }\end{array}$ \\
\hline
\end{tabular}

Karasu (Sakarya/Türkiye) ve Civarının Karayosunu (Briyofit) Florası

\author{
*Gamze GÜRSU' ${ }^{1}$, Barbaros ÇETİN² \\ ${ }^{1}$ Ankara Üniversitesi Fen Fakültesi Biyoloji Bölümü, Tandoğan/Ankara \\ ${ }^{2}$ Dokuz Eylül Üniversitesi Biyoloji Bölümü, Buca/İMIR
}

\title{
Öz
}

Bu çalışmada, Karasu (Sakarya) İlçesi’nden toplanan 180 karayosunu örneğinin teşhis çalışmaları sonucunda, bu çalışmada 12 familya ve 24 cinse ait toplam 36 takson saptanmıştır.

Pottiaceae içerdiği takson sayısı bakımından en zengin familya olurken (11-\%30,5), Brachytheciaceae ikinci sırayı $(7-\% 19,4)$ ve Polytrichaceae $(4-\% 11,3)$ üçüncü sırayı almıştır.

Anahtar Kelimeler: Bryophyta, Flora, Karasu, Karayosunu, Sakarya

\section{The Moss (Bryophyta) Flora of Karasu District (Sakarya/Turkey)}

\begin{abstract}
In this study, 180 moss specimens collected from the Karasu (Sakarya) district, were identified and a total of 36 taxa belonging to 12 families and 24 genera were determined.

While, Pottiaceae is the richest family in terms of the number of taxa (11-\%30,5), Brachytheciaceae has the second order $(7-\% 19,4)$ and Polytrichaceae has the third order $(4-\% 11,3)$.
\end{abstract}

Key Words: Bryophyta, Flora, Karasu, Moss, Sakarya

\footnotetext{
* Corresponding author: gamzegursu199@gmail.com

(C) 2017 All rights reserved / Tüm haklarl saklıdır.

To cite this article: Gürsu G. Çetin B. 2017. The Moss (Bryophyta) Flora of Karasu District (Sakarya/Turkey). Anatolian Bryology. 3(2): 68-74.
} 


\section{Giriş}

Ülkemizde yapılan flora çalışmalarının büyük bir k1smı tohumlu bitkiler üzerinedir. "Flora of Turkey and the Aegean Islands" (Davis ve ark. 1965-1988; Güner ve ark. 2000) adlı eserde Türkiye Eğreltileri ve Tohumlu Bitkilerinin floraları 11 cilt halinde yazılmış olmasına rağmen Yapraklı Karayosunları (Musci) Florası henüz yazılmamıştır. Türkiye'de yapraklı karayosunları ile ilgili ilk çalışmalar yabancı araştırmacılar tarafindan yapılmıştır.

Biyolojik çeşitliliğimizi korumak ve sürdürmek adına kurulan Milli Parkların biyolojik çeşitliliğinin envanterinin çıkarılması tam anlamıyla koruyabilmenin ön şartıdır. Çalışma alanının bir kısmı içerisinde yer alan Acarlar Longozu I. Derece Doğal Sit Alanı ve Maden Deresi Mevkii I-II. Derece Doğal Sit Alanı'dır.

Araştırma alanımıza ait bryofloristik bir çalışmanın bulunmaması; başta Quercus pubescens Willd., Fagus orientalis Lipsky, Castanea sativa Mill., Carpinus betulus L., Sp. Pl. 2: 1753., Fraxinus excelsior L., Populus alba L. (1753) ağaç türlerinden meydana gelen zengin bitki örtüsünün bulunması; Sakarya Nehri Havzası'nda Karasu ile Kaynarca ilçeleri içerisinde yer alan, birçok bitki ve hayvan türüne ev sahipliği yapan Türkiye'nin en büyük ikinci subasar ormanının bulunduğu; çok sayıda sucul alanın oluşturduğu koşullar karayosunlarının gelişmesine uygun bir ortam sağlamakta ve bu bölgenin takson zenginliğini arttırmaktadır. $\mathrm{Bu}$ nedenlerle Karasu İlçesi'nin yapraklı karayosunu yönünden araştırılması amaçlanmıştır.

Karasu, Batı Karadeniz Bölgesinin bittiği, Marmara Bölgesinin başladığı yerde olduğu için iki bölgenin tesiri altında bir iklime sahiptir. Genel olarak, yazları sıcak ve kurak, kışları soğuk ve yağışlıdır. Kış aylarında yağış genelde yağmurludur. Yağış ortalamas1 1.200 mm.'dir (www.karasu.gov.tr).

Briyofit terimi; karayosunları, ciğerotları ve boynuzotlarını içeren bitki grubunu ifade etmek için kullanılmaktadır. Son yapılan moleküler çalışmalar doğtultusunda Briyofitler, Bryobiotina Altalemi
(Subkingdom) altında (Divisio); boynuzotlarını içeren Anthocerotophyta, ciğerotlarını içeren Marchantiophyta ve karayosunlarını içeren Bryophyta olmak üzere 3ölümde incelenmektedir (Glime, 2013).

Dünya üzerinde; karayosunların yaklaşık olarak 12700 türü (Crosby vd. 2000), ciğerotlarının 60008000 türü (Crandall-Stotler and Stotler 2000), ve boynuzsu ciğerotlarının ise yaklaşık olarak 100-150 türü bulunmaktadır (Ursavaş ve Abay 2009). Ülkemizde ise şimdiye kadar yapılan çalışmalar sonucu Musci (Bryopsida) sınıfindan yaklaşık 800 tür ve tür altı takson, Hepaticae (Hepaticopsida) sinıfindan 175 tür ve tür altı takson, Anthocerotae (Anthocerotopsida) sınıfından ise 3 türün kaydı verilmiştir ve bu sayı yapılan çalışmalarla sürekli artmaktadir (Abay vd. 2007a).

\section{Materyal ve Yöntem}

Araştırma alanı olan Karasu İlçesi; Batı Karadeniz Bölgesi'nin bitişi, Marmara Bölgesi'nin başlangıç noktasında yer almaktadır (Şekil 1). Denizden yüksekliği ortalama 31 metredir. $477 \mathrm{~km}^{2}$ yüzölçümüne sahiptir. $41^{\circ} 06^{\prime} 59^{\prime \prime}$ enlem ve $30^{\circ} 42^{\prime}$ 10 " boylam çizgileri arasında yer almaktadır (Şekil 2). Araştırmanın materyalini bu alan içerisinden toplanan karayosunu materyalleri oluşturmaktadır. Karasu'da ormanlar 12,465 hektarlık bir alanı kaplamaktadırlar. İlçenin başlıca yükseltileri; Kızılcık ve Karasu Köyleri arasında yer alan, ilçe merkezinin güneyindeki Demirli Dağı, Resuller, Kancalar ve Konacık köyleri arasında yer alan, ilçe merkezinin batısındaki Resuller Dağı'dır (T.C. İçişleri Bakanlığı, 2011).

Yapraklı Briyofit örnekleri 2010-2011 yılları arasında vejetasyonun farklı dönemlerinde yapılan arazi çalışmaları sırasında toplanmıştır. Örneklerin toplandığı habitatlar, farklı bitki toplulukları, ortamın sulak veya kurak olması, bölgenin coğrafik konumuyla birlikte yükselti farklılıkları da göz önüne alınarak seçilmiştir. Örneklerin toplandığ lokalitelere ait veriler kaydedilmiş olup Tablo 1'de verilmiştir. Çalışma alanı, Henderson (1961)'in Türkiye kareleme sistemine göre A2 karesi içerisinde yer almaktadır (Şekil 2). 


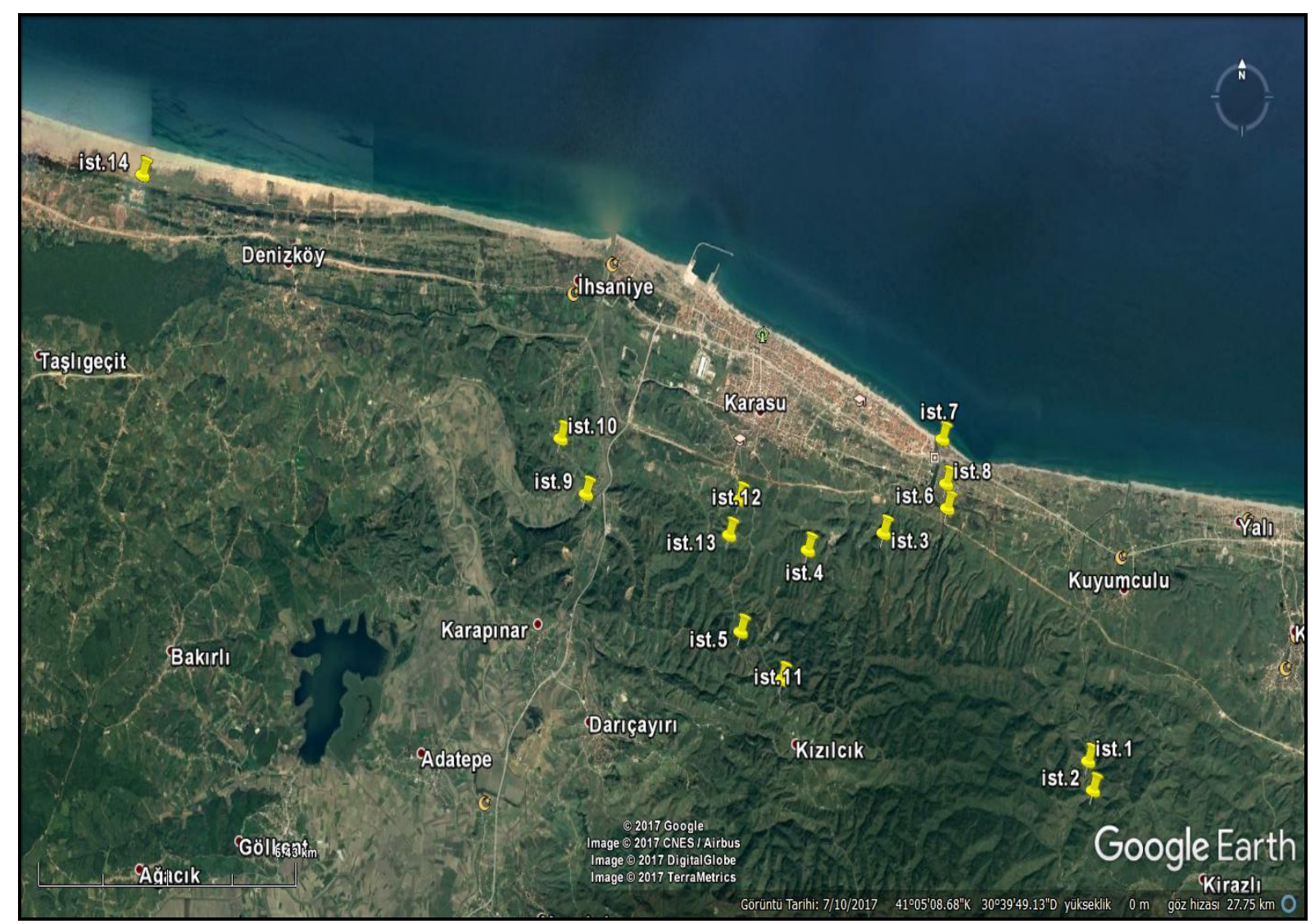

Şekil.1 Karasu İlçe sınırında yer alan araştırma alanı (Google Earth)

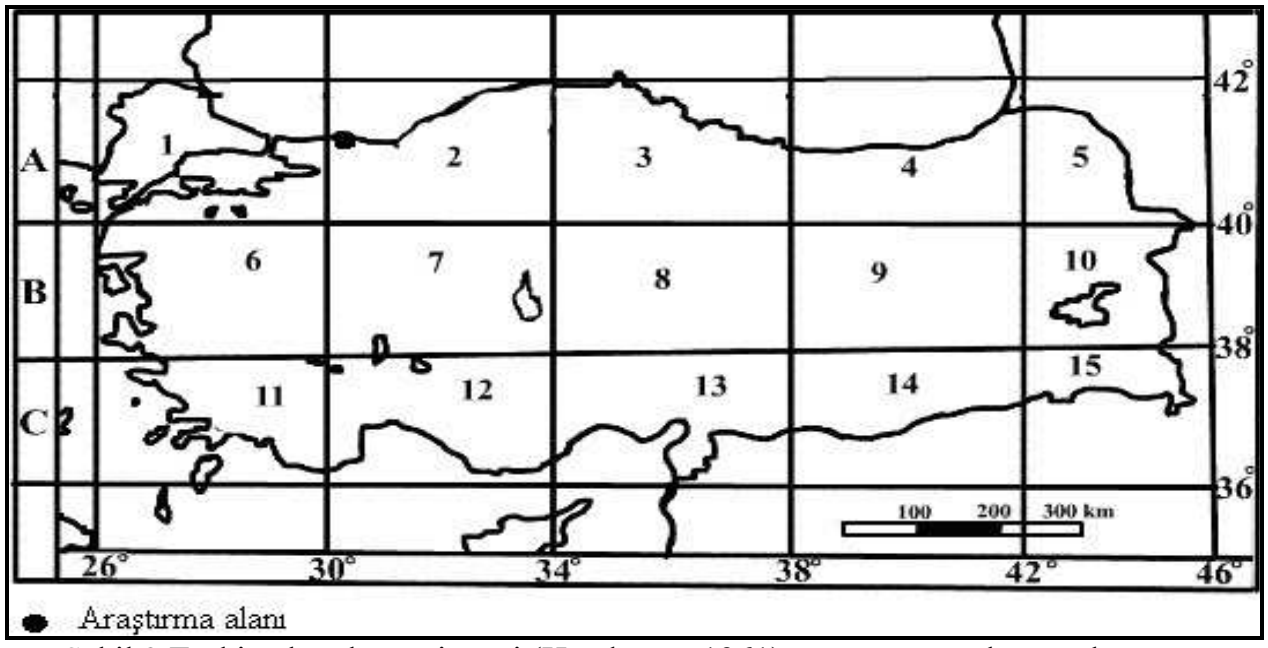

Şekil.2 Türkiye kareleme sistemi (Henderson 1961) ve araştırma alanının konumu

Tablo.1 Lokalite detayları

\begin{tabular}{|c|c|c|c|c|c|}
\hline $\begin{array}{l}\text { İst. } \\
\text { No }\end{array}$ & Tarih & Lokalite & Enlem- Boylam & $\begin{array}{l}\text { Yükseklik } \\
(\mathbf{m} .)\end{array}$ & Vejetasyon Durumu \\
\hline $\mathbf{1}$ & 08.09.2010 & $\begin{array}{l}\text { Maden } \\
\text { Deresi -I }\end{array}$ & $\begin{array}{l}\mathrm{K}: 41^{\circ} 01^{\prime} 46,6^{\prime \prime} \\
\mathrm{D}: 30^{\circ} 47^{\prime} 18,7 "\end{array}$ & $43 \mathrm{~m}$ & $\begin{array}{c}\text { Platanus orientalis, Fagus } \\
\text { orientalis, Carpinus betulus, } \\
\text { Castanea sativa, Quercus cerris, } \\
\text { Populus alba, Juglans } \\
\text { regia ve Corylus avellenea }\end{array}$ \\
\hline 2 & 08.09.2010 & $\begin{array}{c}\text { Maden } \\
\text { Deresi- II }\end{array}$ & $\begin{array}{l}\text { K } 41^{\circ} 01^{\prime} 27,9 " \\
\text { D: } 30^{\circ} 47^{\prime} 23 "\end{array}$ & $89 \mathrm{~m}$ & $\begin{array}{c}\text { Corylus avellenea, Salix alba, } \\
\text { Platanus orientalis, Quercus cerris }\end{array}$ \\
\hline 3 & 21.11.2010 & $\begin{array}{l}\text { Aziziye } \\
\text { Mevkii- I }\end{array}$ & $\begin{array}{c}\mathrm{K}: 41^{\circ} 04^{\prime} 15,4^{\prime \prime} \\
\mathrm{D}: 30^{\circ} 43^{\prime} 40,9^{\prime \prime}\end{array}$ & $81 \mathrm{~m}$ & $\begin{array}{l}\text { Corylus avellenea, Castanea sativa, } \\
\text { Pinus sylvestris, Ulmus glabra. }\end{array}$ \\
\hline
\end{tabular}




\begin{tabular}{|c|c|c|c|c|c|}
\hline 4 & 22.11 .2010 & $\begin{array}{c}\text { Aziziye } \\
\text { Mevkii- II }\end{array}$ & $\begin{array}{l}\text { K: } 41^{\circ} 04^{\prime} 04,8^{\prime \prime} \\
\text { D: } 30^{\circ} 42^{\prime} 19,8^{\prime \prime}\end{array}$ & $97 \mathrm{~m}$ & Juglans regia, Corylus avellenea \\
\hline 5 & 24.01.2011 & $\begin{array}{l}\text { Kızılcıktepe } \\
\text { Mesire } \\
\text { Alanı }\end{array}$ & $\begin{array}{l}\text { K: } 41^{\circ} 03^{\prime} 11,3^{\prime \prime} \\
\text { D: } 30^{\circ} 41^{\prime} 0,7^{\prime \prime}\end{array}$ & $208 \mathrm{~m}$ & $\begin{array}{c}\text { Fraxinus oxyphylla ssp. oxycarpa, } \\
\text { Pinus sylvestris, Salix alba, } \\
\text { Platanus orientalis, Juniperus } \\
\text { communis }\end{array}$ \\
\hline 6 & 25.01 .2011 & $\begin{array}{l}\text { Çamlık } \\
\text { Mevkii }\end{array}$ & $\begin{array}{c}\text { K: } 41^{\circ} 4^{\prime} 31,5^{\prime \prime} \\
\text { D: } 30^{\circ} 44^{\prime} 48,7^{\prime \prime}\end{array}$ & $35 \mathrm{~m}$ & Pinus sylvestris \\
\hline 7 & 25.01 .2011 & $\begin{array}{l}\text { Küçükbogaz } \\
\text { Gölü- I }\end{array}$ & $\begin{array}{l}\text { K: } 41^{\circ} 5^{\prime} 16,1^{\prime \prime} \\
\mathrm{D}: 30^{\circ} 44^{\prime} 43,8^{\prime \prime}\end{array}$ & $3 \mathrm{~m}$ & Populus alba, Acer palmatum. \\
\hline 8 & 25.01 .2011 & $\begin{array}{l}\text { Küçükbogaz } \\
\text { Gölü- II }\end{array}$ & $\begin{array}{l}\mathrm{K}: 41^{\circ} 04^{\prime} 47,7^{\prime \prime} \\
\mathrm{D}: 30^{\circ} 44^{\prime} 47,5^{\prime \prime}\end{array}$ & $2 \mathrm{~m}$ & Pinus sylvestris, Salix sp., \\
\hline 9 & 01.05 .2011 & $\begin{array}{c}\text { Sakarya } \\
\text { Nehri Kıyı1 }\end{array}$ & $\begin{array}{c}\text { K: } 41^{\circ} 4^{\prime} 41,4^{\prime \prime} \\
\text { D: } 30^{\circ} 38^{\prime} 22,7^{\prime \prime}\end{array}$ & $35 \mathrm{~m}$ & $\begin{array}{l}\text { Acer palmatum, Populus alba, } \\
\text { Cornus mas, Juniperus communis. }\end{array}$ \\
\hline 10 & 01.05 .2011 & $\begin{array}{c}\text { Tuzla } \\
\text { Mevkii }\end{array}$ & $\begin{array}{l}\text { K: } 41^{\circ} 05^{\prime} 17,8^{\prime \prime} \\
\mathrm{D}: 30^{\circ} 37^{\prime} 55,9^{\prime \prime}\end{array}$ & $41 \mathrm{~m}$ & $\begin{array}{c}\text { Quercus cerris, Platanus orientalis, } \\
\text { Fagus orientalis, Populus alba. }\end{array}$ \\
\hline 11 & 25.05 .2011 & $\begin{array}{l}\text { Kizılcık } \\
\text { Yolu- Odun } \\
\text { Deposu }\end{array}$ & $\begin{array}{l}\mathrm{K}: 41^{\circ} 2^{\prime} \text { ' 40,9" } \\
\mathrm{D}: 30^{\circ} 41^{\prime} 51,8^{\prime \prime}\end{array}$ & $106 \mathrm{~m}$ & Corylus avellenea, Ficus carica \\
\hline 12 & 08.06.2011 & $\begin{array}{l}\text { Akçagöl } \\
\text { Kıy1 } \\
\text { Çevresi }\end{array}$ & $\begin{array}{c}\mathrm{K}: 41^{\circ} 4^{\prime}{ }^{\prime} 37^{\prime \prime} \\
\mathrm{D}: 30^{\circ} 41^{\prime} 6,6^{\prime \prime}\end{array}$ & $58 \mathrm{~m}$ & Corylus avellenea, Fagus orientalis \\
\hline 13 & 08.06 .2011 & $\begin{array}{c}\text { Akçagöl- } \\
\text { Ormanlık } \\
\text { Alan } \\
\end{array}$ & $\begin{array}{l}\text { K: } 41^{\circ} 0414,7^{\prime \prime} \\
\text { D: } 30^{\circ} 40^{\prime} 55,6^{\prime \prime}\end{array}$ & $42 \mathrm{~m}$ & $\begin{array}{l}\text { Corylus avellenea, Populus alba, } \\
\text { Carpinus betulus, Castanea sativa }\end{array}$ \\
\hline 14 & 24.07 .2011 & $\begin{array}{l}\text { Acarlar } \\
\text { Longoz } \\
\text { Ormanı }\end{array}$ & $\begin{array}{l}\mathrm{K}: 41^{\circ} 08^{\prime} 09^{\prime \prime} \\
\mathrm{D}: 30^{\circ} 30^{\prime} 28^{\prime \prime}\end{array}$ & $5 \mathrm{~m}$ & $\begin{array}{c}\text { Alnus glunitosa, Paliurus } \\
\text { aculeatus, Ulmus campestris, } \\
\text { Fraxinus oxyphylla ssp. Oxycarpa, } \\
\text { Populus alba }\end{array}$ \\
\hline
\end{tabular}

Teşhisi yapılan yapraklı karayosunları zarflara konularak herbaryum örneği haline getirilmiştir. Zarfların üzerine örneği toplayan ve teşhisleri yapan kişinin adı, istasyon bilgisi, familya adı, tür adı, habitat tipi (Tablo.2), fotoğraf numaras1, örnek numarası bilgileri kaydedilmiştir. Kesin teşhisi yapıldıktan sonra herbaryum örneği haline getirilen örnekler ÇETIN'e ait özel koleksiyona dahil edilmiştir

Tablo.2 Habitat tipleri ve kısaltmaları

\begin{tabular}{|l|c|}
\hline \multicolumn{1}{|c|}{ Habitat Tipleri } & Kısaltması \\
\hline Toprak & $\mathrm{S}$ \\
\hline Kaya üzeri & $\mathrm{R}$ \\
\hline Ăgaç üzeri & $\mathrm{T}$ \\
\hline Kütük üzeri & $\mathrm{L}$ \\
\hline Taş üzeri & $\mathrm{B}$ \\
\hline Kum üzeri & $\mathrm{G}$ \\
\hline
\end{tabular}

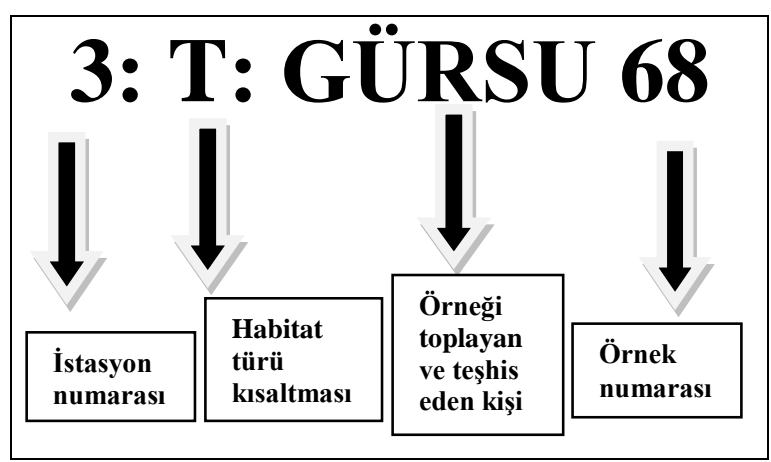

Şekil.3 Örnekleme bilgilerinin kısaltmaları

Briyofit örneklerinin teşhisinde çeşitli flora eserlerinden faydalanılmıştır; The Moss Flora of Britain \& Ireland (Smith 1980-2004), Illustrated Moss Flora of Nordic Mosses. Fasc. 1. (Nyholm 1987), Illustrated Moss Flora of Nordic Mosses. Fasc. 2. (Nyholm 1989), Illustrated Moss Flora of Nordic Mosses. Fasc. 3. (Nyholm 1993), Illustrated Moss Flora of Nordic Mosses. Fasc. 4. (Nyholm 1998), The Bryophyte Flora of Israel and Adjacent Regions (Herrnstadt and Heyn 2004), Kürschner ve Frey, 2011, Moss Flora of China (Vol.3) (English version) Grimmiaceae-Tetraphidaceae (Gao Chien 2003), Mosses and Liverworts of Britain and Ireland a field guide (Atherton vd. 2010) isimli eserlerden faydalanılmıştır (Ursavaş ve Öztürk, 2016). Checklist verilişinde Ros ve ark. (2013) "An annotated checklist of the mosses of Europe and Macaonesia” isimli eserinden yararlanılmıştır. Taksonların, Henderson (1961) kareleme sistemine göre A2 karesi için yeni olup olmadıkları konusunda ise Ursavaş ve Abay (2009)'ın çalışmaları dikkate alınmıştır.

\section{Bulgular}

2010-2011 yılları arasında yapılan arazi çalışmaları sonucunda toplam 180 örneğin teşhisi sonucunda 12 familya ve 24 cinse ait 36 takson tespit edilmiştir. 


\section{Floristik Liste \\ BRYOPSIDA}

1. Polytrichaceae P. BEAUV., MAG. ENCYCL. Atrichum undulatum (Hedw.) P. Beauv. (12:S:GÜRSU153)

Pogonatum aloides (Hedw.) P. Beauv. (9:R:GÜRSU102)

Polytrichum juniperinum Hedw. (11:S:GÜRSU149, 13:S:GÜRSU161)

Polytrichum piliferum Hedw. ( $P$. piliferum var. hoppei (Hornsch.) Haller) (12:S:GÜRSU156)

2. Funariaceae Schwagr

Funaria hygrometrica Hedw. (12:B:GÜRSU135)

3.Grimmiaceae Arnott

Schistidium trichodon (Brid.) Poelt.

(3:R:GÜRSU68)

4. Ditrichaceae Limpr.

Ceratodon purpureus (Hedw.) Brid. (3:R:GÜRSU73, 4:R:GÜRSU92)

5. Pottiaceae Schimp.

Eucladium verticillatum (Brid.) Brunch \& Schimp. (2:R:GÜRSU49)

Tortella squarrosa (Brid.) Lindb. (13:G:GÜRSU180)

Tortella tortuosa (Hedw.) Limpr., Laubm. Deutschl. (1:R:GÜRSU13)

Barbula convoluta Hedw. (11:S:GÜRSU121)

Barbula unguiculata Hedw. (13:S:GÜRSU179)

Didymodon fallax Hedw. (9:R:GÜRSU105)

Didymodon nicholsonii Culm. (9:R:GÜRSU116)

Syntrichia ruralis (Hedw.) F. Weber \& D. Mohr. (13:G:GÜRSU176)

Tortula muralis Hedw. (9:B:GÜRSU129)

Tortula inermis (Brid.) Mont. (12:B:GÜRSU136)

Tortula subulata Hedw. (2:B:GÜRSU39)

6. Cinclidotaceae

Cinclidotus riparius (Host ex Brid.) Arnott (2:R:GÜRSU23)

7. Orthotrichaceae Arnott.

Orthotrichum affine Schrad. ex Brid.

(13:L:GÜRSU171)

8. Bryaceae Scwagr.

Ptychostomum capillare Hedw. (4:R:GÜRSU46)

Ptychostomum pallens Sw. (9:S:GÜRSU112)

9. Amblystegium Schimp.

Amblystegium serpens (Hedw.) Schimp.

(5:T:GÜRSU55)

Leptodictyum riparium (Hedw.) Schimp.

(11:S:GÜRSU137)

10. Brachytheciaceae Schimp.

Pseudoscleropodium purum (Hedw.) M. Fleisch. Broth. (6:S:GÜRSU72)

Rhynchostegium confertum (Dicks.) Schimp. (9:S:GÜRSU109, 11:S:GÜRSU143)

Sciuro-hypnum plumosum (Hedw.) Schimp.

(11:T:GÜRSU128, 12:L:GÜRSU144)

Brachythecium albicans (Hedw.) Schimp.

(4:R:GÜRSU95)

Brachythecium glareosum (Spruce) Schimp. (6:S:GÜRSU31)
Eurhynchiastrum pulchellum var. diversifolium (2:R:GÜRSU35)

Homalothecium sericeum (Hedw.) Schimp. (1:T:GÜRSU16)

11. Hypnaceae Schimp.

Calliergonella cuspidata (Hedw.) Loeske (13:S:GÜRSU178)

Hypnum cupressiforme var. cupressiforme Hedw. (1:L:GÜRSU11)

Hypnum cupressiforme var. lacunosum (Brid.) G. F. Hoffmann ex Brid. (4:L:GÜRSU64)

12. Neckeraceae Hedw.

Alleniella complanata (Hedw.) S. Olsson, Enroth \& D. Quandt (1:T:GÜRSU123, 2:T:GÜRSU47)

Exsertotheca crispa (Hedw.) S. Olsson, Enroth \& D. Quandt (1:R:GÜRSU17).

\section{Sonuç}

Karasu (Sakarya) İlçesi'nden 2010 ve 2011 yılları arasında, vejetasyonun farklı zamanlarında toplanan 180 karayosunu örneğinin değerlendirilmesi sonucu 12 familyaya ait 36 takson tanımlanmıștır. Henderson (1961) tarafından benimsenen Türkiye kareleme sistemine göre A2 karesi için, yeni kare kaydı belirlenememiştir.

Karasu İlçesi'nde yapılan arazi çalışmalarında toplanan yapraklı karayosunu örneklerinin teşhisi sonucunda tespit edilen taksonlara ait cins ve bunların da bağlı olduğu familyalara ilişkin bilgiler Tablo.3' de verilmiştir.

Tablo.3 Araştırma alanından bulunan taksonların familyalara göre dağılımı

\begin{tabular}{|l|c|c|}
\hline \multicolumn{1}{|c|}{ Familya } & $\begin{array}{c}\text { Takson } \\
\text { Sayıs }\end{array}$ & $\begin{array}{c}\text { Toplam Takson } \\
\text { Sayısına Oranı } \\
(\mathbf{\%})\end{array}$ \\
\hline Pottiaceae & 11 & 30,5 \\
\hline Bracyhtheciaceae & 7 & 19,4 \\
\hline Polytrichaceae & 4 & 11,3 \\
\hline Hypnaceae & 3 & 8,7 \\
\hline Amblystegiaceae & 2 & 5,5 \\
\hline Bryaceae & 2 & 5,5 \\
\hline Neckeraceae & 2 & 5,5 \\
\hline Cinclidotaceae & 1 & 2,7 \\
\hline Ditrichaceae & 1 & 2,7 \\
\hline Grimmiaceae & 1 & 2,7 \\
\hline Funariaceae & 1 & 2,7 \\
\hline Orthotrichaceae & 1 & 2,7 \\
\hline TOPLAM & $\mathbf{1 2}$ & $\mathbf{1 0 0}$ \\
\hline
\end{tabular}

Bu çalışma sonuçları benzer özellikler taşıyan ve A2 karesi içerisinde yer alan Karadeniz ve İç Anadolu geçiş kuşağında bulunan; Ilgaz Dağı Milli Parkı (Abay ve Çetin 2003), Kızılcahamam Soğuksu Milli Parkı (Uyar ve Çetin 2001a), Çankırı EldivanKaradere (Abay, [2005] 2006) ve Çankırı Eldivan Dağı (Keçeli ve Çetin 2000) Karadere çalışmalarıyla da kıyaslanmıştır (Tablo.4). 
Tablo.4 Karasu İlçesi ile A2 karesi içerisinde yer alan alanların familyalarının kıyaslanması

\begin{tabular}{|l|c|c|c|c|c|c|c|c|c|c|}
\hline & \multicolumn{2}{|c|}{$\begin{array}{c}\text { Karasu } \\
\text { (SAKARYA) } \\
\text { (A2) }\end{array}$} & \multicolumn{2}{c|}{$\begin{array}{c}\text { Ilgaz Dağı Milli } \\
\text { Parkı } \\
\text { (A2) }\end{array}$} & \multicolumn{2}{c|}{$\begin{array}{c}\text { Kızlcahamam } \\
\text { Soğuksu Milli } \\
\text { Parkı (A2) }\end{array}$} & \multicolumn{2}{c|}{$\begin{array}{c}\text { Çankırı } \\
\text { Eldivan Dağı } \\
\text { (A2) }\end{array}$} & \multicolumn{2}{c|}{$\begin{array}{c}\text { Çankırı } \\
\text { Eldivan } \\
\text { Karadere } \\
\text { (A2) }\end{array}$} \\
\hline Familyalar & $\begin{array}{c}\text { Takson } \\
\text { sayısı }\end{array}$ & $\%$ & $\begin{array}{c}\text { Takson } \\
\text { sayısı }\end{array}$ & $\%$ & $\begin{array}{c}\text { Takson } \\
\text { sayısı }\end{array}$ & $\%$ & $\begin{array}{c}\text { Takson } \\
\text { sayısı }\end{array}$ & $\%$ & $\begin{array}{c}\text { Takson } \\
\text { sayısı }\end{array}$ & $\%$ \\
\hline Pottiaceae & 11 & 30.5 & 15 & 13.7 & 19 & 16.4 & 14 & 23.3 & 14 & 31.1 \\
\hline Brachytheciaceae & 7 & 19.4 & 15 & 13.7 & 20 & 17.2 & 11 & 18.3 & 6 & 13.3 \\
\hline Grimmiaceae & 1 & 2.7 & 7 & 6.4 & 13 & 11.2 & 5 & 8.3 & 4 & 8.8 \\
\hline Amblystegiaceae & 2 & 5.5 & 5 & 4.6 & 7 & 6.0 & 4 & 6.6 & 4 & 8.8 \\
\hline Leskeaceae & - & - & 4 & 3.6 & 4 & 3.4 & - & - & - & - \\
\hline Hypnaceae & 3 & 8.7 & 9 & 8.2 & 3 & 2.6 & 4 & 6.6 & 3 & 6.6 \\
\hline Orthotrichaceae & 1 & 2.7 & 4 & 3.6 & 10 & 8.6 & 2 & 3.3 & 3 & 6.6 \\
\hline Mniaceae & - & - & 9 & 8.2 & 1 & 0.9 & - & - & - & - \\
\hline
\end{tabular}

Takson sayısı bakımından en kalabalık familyalar; Pottiaceae (11 takson), Brachytheciaceae (7 takson), Polytichaceae (4 takson), Hypnaceae (3 takson) olup çalışma alanında tanımlanan taksonların \% 69,9'unu oluşturmaktadırlar. Bu kıyaslama sonuçlarına göre; Pottiaceae familyasının çalışma alanında takson sayısı en zengin familya olduğu görülmektedir. Pottiaceae familyası üyelerinin yüksek oranda temsil edilmesinin nedeni ise farklı ortam koşullarına adapte olabilen çok sayıda tür içermeleri ile açıklayabiliriz (Alataş ve Uyar, 2015). Alanda en yaygın olarak gözlemlenen türler; Barbula convoluta, Tortella tortuosa, Didymodon fallax, Syntrichia ruralis, ve Brachythecium plumosum 'dur. Araştırma alanından toplanan familyaların \%47,3‘ü akrokarp, \%52,7‘i ise pleurokarptır. Pottiaceae familyası üyeleri gibi akrokarp gelişme gösteren türler çoğunlukla, yaprak uçlarında hair-pointe sahiptir ve sık yastıklar biçiminde gelişme gösterdikleri için uzun dönem sıcaklığa ve kuraklığa daha dayanıklıdırlar. Kuraklık artışının akrokarp karayosunlarının daha fazla türle temsil edilmesine olanak sağladığı, birçok çalışmada belirtilmiştir (Nyholm ve Wigh, 1973). A2 karesi içerisinde yer alan araştırma alanlarından Kızılcahamam Soğuksu Milli Parkında Pottiaceae, Brachytheciaceae, Grimmiaceae ve Orthotrichaceae familyaları diğer araştırma alanlarına oranla daha çok bireyle temsil edilmektedir.

Sonuç olarak, briyofit florası araştırılmamış olan Karasu İlçesi'nin briyofit çeşitliliği bu çalışma ile çıkarılarak Türkiye Briyofit Florasına katk1 sağlanmıştır. Araştırma alanının değişik ortam şartlarını bir arada bulunduruyor olması bryofit çeşitliliği için önemli bir parametredir. Karasu İlçesi’nin kumul alanları 122 Önemli Bitki Alanı listesi içerisinde yer almaktadır. Türkiye'nin en büyük ikinci subasar ormanının (Acarlar Longoz Ormanı) bulunduğu; farklı sulak alanlarla çevrili alanların oluşturduğu şartlar karayosunlarının gelişmesine uygun bir ortam sağlamakta ve bu bölgenin tür zenginliğini ortaya çıkarmaktadır. Bölgede koruma altına alınan alanlar; insan faaliyetlerinden olumsuz etkilenmekte ve bitki türleri üzerinde büyük bir baskı oluşturmaktadır.

\section{Kaynaklar}

Abay, G. and Çetin, B. 2003. The moss flora (musci) of Ilgaz Mountain National Park.Turkish Journal of Botany, 27:321-332.

Abay, G. [2005] 2006. Contributions to the moss flora (Musci) of Çankırı Province (EldivanKaradere). Ot Sistematik Botanik Dergisi. 12:175-186.

Abay, G., Uyar, G., Çetin, B. and Keçeli, T. 2007a. Kaçkar Dagıları Bryofit Florası. TBAG 2404 (104T014) nolu proje, 229 s, Ankara.

Atherton I. Bosanquet S. Lawley M. 2010. Mosses and Liverworts of Britain and Ireland a field guide. British Bryological Society. United Kingdom.

Alataş, M., Uyar,G. 2015. The Bryophyte flora of Abant Mountains (Bolu/Turkey). Biological Diversity and Conservation, 8(1):35-43.

Chien G. 2003. Moss Flora of China, English version, Volume 3: GrimmiaceaeTetraphidaceae. Missouri Botanical Garden, USA.

Crandall-Stotler, B. and Stotler, R. E. 2000. Morphology and classification of the

Marchantiophyta. In Bryophyte Biology, ed. A.J. Shaw and B. Goffinet, pp.

21-70. Chambridge: Chambridge Univerity Press.

Davis, P.H., Mill, R. R., Tan, K. 1965-1988. Flora of Turkey and The East Aegean Islands. Vol:IX. Edinburg Univ. Press. Edinburgh, England.

Glime J.M. 2013. Bryophyte Ecology. Ebook sponsored by Michigan Technological University and the International Association of Bryologists.

Güner, A., Özhatay, N., Ekim, T., Başer, K. H. C., 2000. Flora of Turkey and the East Aegean Islands. vol 11, Edinburgh University Press, 2001. 
Henderson, D.M. 1961. Contribution to bryophyte flora of Turkey IV. Notes RoyalBotanical Garden Edinburgh, 23:263-278.

Herrnstadt, I. and Heyn, C.C. 2004. The Bryophyte Flora of Israel and Adjacent Regions. The Israel Academy of Sciences and Humanities, Jerusalem, $719 \mathrm{~s}$.

Hill MO. Bell N. Buruggeman-Nannenga MA. Brugues M. Cano MJ. Enroth Flatberg KI. Fraham J-P. Gallego MT. Garilleti R. Guerra J. Hedenäs L. Holyoak DT. Hyvönen J. Ignatov MS. Lara F. Mazimpaka V. Munoz J. Söderström L. 2006. An annotated checklist of the mosses of Europe and Macronesia. Journal of Bryology. 28: 198-267.

Keçeli, T., Çetin, B. 2000. The Moss Flora of Çankır1-Eldivan Mountain. Turk J Bot. 24: 249-258.

Kürschner, H., Frey, W. 2011. Liverworts, Mosses and Hornworts of Southwest Asia 240, in der Gebr. Borntraeger Verlagsbuchhandlung. Stutgart.

Nyholm, E. And Wigh, K. (1973). Cytotaxonomical Studies in Some Turkish Mosses. Lindbergia, 2:105-113.

Nyholm, E. 1987. Illustrated Flora of Nordic Mosses Fasc. 1. Swedish Oikos Editorial Office, $72 \mathrm{~s}$, Copenhagen.

Nyholm, E. 1990. Illustrated Flora of Nordic Mosses Fasc. 2. Swedish Oikos Editorial Office, $68 \mathrm{~s}$, Copenhagen.

Nyholm, E. 1993. Illustrated Flora of Nordic Mosses Fasc. 3. Swedish Oikos Editorial Office, 101 s, Copenhagen.

Nyholm, E. 1998. Illustrated Flora of Nordic Mosses Fasc. 4. Swedish Oikos Editorial Office, 160 s, Copenhagen.

Ros R. M. Mazimpaka V. Abou-Salama U. Aleffi M. Blockeel T. L. Brugués M. Cros R. M. Dia M. G. Dirkse G. M. Draper I. et al.. 2013. Mosses of the Mediterranean, an annotated checklist. Cryptogamie Bryologie. 34: 99283.

Smith, A.J.E. 1980. The Moss Flora of Britain and Ireland. Cambridge University Press, $706 \mathrm{~s}$.

Smith, A.J.E. 2004. The Moss Flora of Britain an Ireland. Cambridge University Press, $1012 \mathrm{~s}$.

Ursavaş, S., Abay, G. 2009. Türkiye'nin A2 karesinin karayosunları (Musci) kontrol listesi. Bartın Orman Fakültesi Dergisi, 16(2): 33-43.

Ursavaş, S., Öztürk E. 2016. Çankırı Karatekin Üniversitesi, Orman Fakültesi, Araştırma ve Uygulama Ormanında Ölü Ağaçlar üzerinde Tespit edilen Karayosunlar. Anatolian Bryology. 2:1-2, 2016.

Uyar, G., Çetin, B. 2001a. The Moss Flora of Ankara-Kızılcahamam Soğuksu National Park. Turk J Bot. 25, 261-273.
T.C. İçişleri Bakanlığı Karasu Kaymakamlığı. Karasu İlçesi Coğrafi Konumu. Erişim Adresi: http://www.karasu.gov.tr/cografiyapisi Erişim tarihi: (12.09.2017)

Google Earth http://earth.google.com/ Erişim tarihi: (15.09.2017). 